Published in: Composites Part B: Engineering

Accepted: 13 January 2020

DOI: https://doi.org/10.1016/j.compositesb.2020.107766

\title{
Damage tolerance of CFRP airframe bolted joints in bearing, following bolt pull- through failure
}

\author{
Ioannis K. Giannopoulos ${ }^{a^{*}}$, Kaelan Grafton ${ }^{\text {a }}$, Shijun Guo ${ }^{\text {a }}$, Howard Smith ${ }^{\text {a }}$ \\ ${ }^{a}$ Centre of Excellence for Aeronautics, School of Aerospace, Transport and \\ Manufacturing, Cranfield University, Cranfield, MK43 0AL, UK
}

\begin{abstract}
The experimental study presented herein, investigated the residual strength of bolted joints on Carbon Fiber Reinforced Polymer (CFRP) airframe structures within the context of structural damage tolerance and airworthiness regulations. The damage scenario assumed, subjected a series of bolted joint CFRP laminate specimens to quasistatic bearing loading following bolt pull-through failure events of different magnitude. Representative CFRP laminate specimens manufactured from AS7/8552 carbon fiber/epoxy matrix system were artificially damaged under bolt pull-through loading, following the herein proposed modifications to the current pull-through ASTM testing procedure. The specimens were subsequently tested in static bearing loading for examining the specimen residual bearing strength. The residual joint bearing strength was related to the displacement travelled passed the initial failure stage in pull-through mode and was measured up to a maximum of a 13\% decrease for the tested samples and the maximum damage imposed. The study explored of safe utilization of bolted joints at higher operating loading levels within the context of the current airworthiness regulations. The inherent damage arrest features of the joints were highlighted. The study concluded with comments and suggestions on the expansion of the current utilization spectrum of damaged bolted joints from pull-through loading in airframe design, bound by the current airworthiness certification requirements.
\end{abstract}

Keywords: Structural joints; D. Mechanical testing; B. Strength; B. Damage Tolerance; *Corresponding author

Email: i.giannopoulos@cranfield.ac.uk; Tel: +44 (0) 1234754692 


\section{Introduction}

The aerospace vehicle design sector has embraced the application of Fiber Reinforced Polymer materials (FRP) for some decades now. These materials provided the FRP airframe structural designs with enhanced strength and stiffness regarding the most traditional ones made of aluminum alloys and/or other metallic materials. For most designs, a reduction in the structural weight was achieved especially for the structures with defined load paths, benefiting from the directional property tailoring of the unidirectional laminate FRP materials.

The production method for classic aluminum alloy airframe structures is to assemble forged, machine formed and thin sheet of aluminum alloy components together, in forming larger structural assemblies fastened by bolts and rivets. It has been recognized that the fewer the joints in such structures, the stiffer and the lighter the design is, the longer the life of the structure generally and the fewer the problems encountered in service $[1,2]$. There are nevertheless limitations to the size of the structural components that could be produced as single structural items prior to assembly for avoiding excessive fastening and riveting.

With the introduction of FRPs, new manufacturing concepts have emerged. The FRP material itself is generated while the structural component is being manufactured, by curing of the composite matrix within or outside oven/autoclave chambers. The idea of generating complete airframes during a single manufacturing stage started to be quite tempting since the conception in the application of the FRPs in airframe manufacturing. Generally, larger structural parts are generated from FRPs but there are limitations to this single stage production process as well. The current status for the majority of FRP airframe components in the aviation industry, for most of the cases that have not been cured or co-cured with their mating part, is to assemble them by the use of bolts. Riveting is not a preferred method for FRP laminate assembly mainly due to the high transversal loading incurred during the fastening/forming process, loading which most of the FRP laminates are relatively intolerant to $[1,4]$. Adhesive bonding can be regarded as another means of assembling, but currently poses a lot of certifications issues especially to the certification of civil aircraft.

Bolted joints on FPRs have been criticized as not being very efficient means of assembling structural components. Joint efficiency is judged by the ratio of the actual 
loading transferred through the joined structure versus the load transferred had the structure been uninterrupted without the presence of any joining means. In that respect, FRP structures can reach a ratio of 0.4 while similar arrangement in aluminum structures can reach the level of $0.65[1,4]$. On many occasions though, when comparing the weight per unit length of assembled structures for carrying the same amount of loading, FRP bolted structures, as a complete assembly, weight less than a supposed substitute made of aluminum alloys.

Amongst the possible bolted joint failure modes [1,2,4], airframe design favors bearing failure [2,4]. Design recommendations regarding edge distances, fastener spacing, thickness and layup of the laminate, will safeguard the bolted structure from failing under different failure modes than bolt bearing. Bolted joints on CFRP structural elements are not designed in general to receive transverse loading along the laminate thickness. Transverse loading will be a component of the loading eccentricity generated in single lap joints; it can result from manufacturing and assembly tolerances mismatches or defects; it can also be generated from thermal expansion and mismatch between mated components; be the result of non-anticipated structural overloading; finally it could occur from foreign object impact. On many occasions, such failure events have been reported from in service Non Destructive structural Inspections (NDI), hence the question of the residual joint strength and safe joint utilization has arisen.

The concept of "damage tolerant design" has been conceptualized for some decades. This engineering design and sizing approach started to be applied to metallic structure fatigue critical locations, following the realization that a structure cannot be free of defects and regular inspection should occur at scheduled intervals during the structure lifecycle [4]. In structures made of metallic materials, damage tolerance design in essence is accepting the existence of supposed cracks at critical locations that propagate under cyclic loading. In structures currently made from FRP materials and under current approved design and certification specifications [4,5,6], it has more of a meaning of meeting the imposed structural performance requirements, with the structure being damaged to a certain extent by containing various damage types at sizes representative of manufacturing errors and/or damage from usage under the expected service environment.

The aerospace industry has been very careful in the sizing of structures made of FRP materials, making sure that enough reserve strength is always present even in the event of 
adverse conditions. Currently, the industry is pushing towards exploring the safe utilization boundaries of FRPs with greater confidence, making use of the inherent damage tolerance features of the CFRP materials wherever applicable. Succeeding in understanding and designing for predictable response of FRP structures at their damaged state, will eventually lead to the design of lighter and safer aircraft vehicles.

The experimental study presented herein, aimed at exploring the damage tolerance of bolted joints on FRP laminates by experimentally measuring the residual strength in bolt bearing loading, following an assumed bolt pull-through failure event scenario. The material for specimen manufacture used was unidirectional HexPly pre-impregnated (pre-preg) AS7/8552 carbon fiber /epoxy matrix tape. This material is currently used on a number of civil transport airframes. The study places the damage tolerance scenario within the context of airframe design and civil airworthiness certification regulations. It aimed at investigating the possible expansion of the current bolted joint utilization spectrum by showcasing the results of the current study. It also proposed the application of a modified testing procedure for exploring the damage tolerance characteristics of bolted joint on FRP laminates under the specified damage sequence scenario.

\section{Experimental procedures}

The aim of this part of the study was to artificially inflict representative damage resulting from bolt pull-through loading at various loading and damage levels. This loading, which is along the thickness of the laminated CFRP plate, would then be removed, to give its place to a subsequent bearing tensile load along the specimen major longitudinal direction. This two-step experimental process is sketched in figure 1. The crosshatched area underneath the bolt depicted in figure 1a, signifies the damage resulting from pull-through testing, while the hatched area in figure $1 \mathrm{~b}$, signifies the superimposed effect of bearing failure on the already damaged laminate being previously subjected to pull-through. The two-step experimental procedure would measure the residual strength in bearing at various pull-through damage levels, depending on the total bolt displacement travelled along the laminate thickness direction during pull-through. The study presented herein did not focus on the loading interaction between pull-through and bearing loading. It was aimed at generating an understanding of the residual bearing strength in a CFRP bolted connection that had prior been 
damaged from a pull-through event or from failure events causing similar damage types, like foreign object low velocity impacts [7]. The study addressed, for example, engineering concession cases where structural components have exhibited such damage and the bearing loading capacity of the bolted joint needs to be re-assessed. This experimental procedure could be employed for generating more realistic residual bearing strength data for design for bolted joints expected to carry minor loads in the transverse direction and pull-through failure might be experienced within the component structural lifecycle,

\subsection{Bolt pull-through testing procedures and research findings}

A standardized testing method for deriving the pull-through strength of bolted joints on FRP laminated composites has been documented under ASTM D7332 [8]. This procedure has been issued by the American Society for Testing and Materials, in accordance with Composites Material Handbook CMH-17 [9]. The key element captured during testing is the response in terms of the pull-load-to-failure vs displacement curve at the bolt location, when the bolt is pulled along the through-thethickness direction of the plate. Initial/subcritical failures and final failure of the joint can be evidenced on the load-displacement curve via minor/major drops in the load or variations in the curve tangency exceeding prescribed amounts of load differences and/or stiffness drops. Research in the public domain $[10,11]$ has presented, for some material systems, the correlation between the microscopic material behavior of the fibrous composite laminates in the plate with the various significant failure events on the load-displacement graph. A good understanding of the microscopic failure mechanisms has been generated which in broad terms has many similarities to the damage caused by low velocity impact events on FRP laminated plates [7]; relative thin laminates experience failure related to bending deformation while for relative thicker ones, shear damage is a more profound failure mode. The location of the shear damage usually starts somewhere along half the plate thickness where the shear internal loading is larger; it emanates from a crevice formed by intra-laminar shear failure and is going outward from the bolt in the form of an inter-laminar delamination, resembling the peanut shaped curves of low velocity impacts [7] for Uni-Directional (UD) laminates. 
Failure attributed to bending deformation is related to inter-laminar tension failure in the laminates subjected to the tensile part of the bending in the plate. Bending and shear failure modes can occur simultaneously depending on the specimen design, material property parameters and the loading level. The bigger the load, damage becomes widespread consisting of shear and tension failures, intra and inter-laminar interactions are bridging [10, 11]. Similarly, various numerical investigations [12,13] have provided with further insights to the failure locations and failure modes in the pull-through loading scenario, partially reinforcing the above mentioned experimental results.

\subsection{Modification to the existing pull-through testing procedure}

Within the ASTM D7332 testing procedure, two fixture methods are proposed which are clamping the composite plate subjected to the bolt pull-through in a slightly different manner. In order to cope with the requirements of the current study, the bolted specimens to be designed and subjected to bearing loading per ASTM D5961 [14], the pull-through procedure had to be modified. The herein proposed alterations to the method relate to method B of ASTM D7332.

In the original testing specification of the testing procedure, the specimens required are square in plan form with dimension ranging from $68 \times 68 \mathrm{~mm}$ up to $108 \times 108 \mathrm{~mm}$ depending on the specimen geometry, more importantly on the plate thickness and bolt diameter. In ASTM D7332 method B, the bolted plate is pulled by the bolt through a circular hole of dimensions ranging from $34 \mathrm{~mm}$ up to $75 \mathrm{~mm}$ in diameter. The FRP laminated plate specimen under this loading case is subjected to a decreasing in magnitude internal shear load distribution along the radial direction, inversely proportional to the radial distance from the center of the bolt and in a bi-directional internal moment load, the description of which can be found in reference [15]. The internal loading in the plate is specific to the boundary conditions and in this case extends from the bolt location until the supported edge at the fixture.

The extents of boundary supports in pull-through testing may interfere with the damage size and type inflicted on the specimen. As described within ASTM D7332, the procedure is for benchmarking the response of the FRP laminates in pull-through and for material data derivation and that actual structural detail response under pull-through 
can potentially deviate from testing due to the different boundary conditions. In order to cope with the requirements of this study, the jig for the pull-through testing was designed smaller in diameter than the prescribed one in ASTM D7332, in order to accommodate the bolted specimens subjected to bearing loading designed per ASTM D5961. The fixture's diameter that supports the specimen under the pull-through process, was redesigned with the aim of having the generated damage engulfed within that diameter, as shown in figures $2 \mathrm{a}$ and $2 \mathrm{~b}$.

Another alteration to the existing testing procedure was to subject the specimens to "push" rather than "pull" load, shown in figure 2c. The change in the applied loading direction alleviated the problem of having to deal with the bolt threading failure modes. A number of different fixture diameters, similar to the one shown in figure $2 \mathrm{a}$ were tested and it was found that for the material and specimen design tested, the specimen load/displacement curve along with the types and locations of damage generated were not affected by the diameter.

The effectiveness of proposed modifications to the original ASTM D7332 method B procedure where monitored following the below suggested metrics:

- The load displacement chart resulting from the push-through procedure having smaller fixtures in diameter, displayed similar characteristics to the one prescribed in ASTM D7332. Namely, there was a distinctively marked initial failure with a major load drop, followed by a second trough and the complete disintegration of the specimen. An example of such a representative load displacement curve is shown in figure 3.

- The extent of the damage resulting from the push-through failure was contained within the fixture supporting diameter, displayed in figure 4.

- The damage modes experienced via sectioning and optical-microscopy resembled the ones reported in the literature $[10,11]$.

It has to be stated that the above mentioned results were specific to the material and specimen design parameters. Variations in the mechanical and damage behavior is to be expected for specimen made of other FRP materials, having different thickness and layup configurations. 
Push-through load/displacement graphs using fixtures of different diameters $(22,24$ and $26 \mathrm{~mm}$ ) exhibited similar behavior according to the metrics stated above.

\subsection{Summary to the proposed testing modifications}

The resulted proposed testing procedure based on the original ASTM D7332 but modified in terms of the smaller diameter in the specimen support fixture and the direction of the load application, have not resulted in a procedure for pull-through strength material property derivation. The aim was to be able to inflict representative pull-through damages on specimen that would subsequently be subjected to quasi-static bearing loading. Hence the pull-through fixture had to be scaled down in order to be compatible with the dimension of a bearing specimen per ASTM D5961. Important to the experimental validation of the proposed modifications presented herein, was to provide with enough proof in the similarity of the load/displacement curve and the assorted damage modes experienced by the testing fixtures described in ASTM D7332 for meeting the needs of the current study.

\subsection{The bearing strength test of the damaged specimens}

The double lap joint arrangement was chosen for bearing strength testing, shown in figure 5a. That arrangement was chosen for avoiding mixing the secondary bending and pull-through effects emerging from the non-symmetric single lap joint configuration. In most airframe structures design cases, single or multi-row, single lap joints are applied for assembly, hence in real practice and even under in plane loading, there is always a component of pull-through loading embedded in a single lap joint.

Some important definitions:

- Bearing stress is a reference stress level, defined as the load carried by the joint, divided by the bolt-hole diameter and the specimen thickness.

According to ASTM D5961 testing method, under static loading conditions:

- Bearing strength is defined as the value of bearing stress occurring at a significant event on the bearing stress / bearing strain curve. The $2 \%$ offset strength is prescribed in the standard while the term "significant" has been subjected to interpretation by Camanho and Lambert [16], where the 5\% in stiffness drop has been proposed. The actual definition of the bearing strength is not going to influence the output of this study. 
- Ultimate bearing strength is the value of bearing stress at the maximum force capability of a bearing specimen.

\section{Experimental testing}

For meeting the requirement of the study and the quick turnaround time required for drafting the joint structural response at a preliminary stage, a total of 16 specimens were manufactured and tested. Specimen material was AS7/8552 HexPly® prepreg unidirectional tape, with nominal laminate thickness of $0.145 \mathrm{~mm}$. Twenty four layers quasi-isotropic layup configuration [45 $90-45$ 0]3s was used, leading to specimen thickness of approximately $3.5 \mathrm{~mm}$. The bearing loading testing procedure ASTM D5961 was followed for specimen geometry and design. The fastener used for both push-through and bearing testing where under NASM27039 specification, which dictates the design characteristics of this cross recess head, pan head structural bolt. The bolt diameter was $6.35 \mathrm{~mm}$, made of A286 steel having cadmium plating.

The quasi-statically applied loading in push-through and bearing tests were performed on an Instron servo-hydraulic testing machine. The testing was displacement controlled with a fixed rate of $0.5 \mathrm{~mm} / \mathrm{min}$. During testing, load and cross head displacement data were recorded. The bearing testing loading direction was aligned with the zero degree layers of the quasi-isotropic specimen as per the applicable ASTM D5961. Variation in the load application with respect to the major laminate axis can affect the static bearing strength of the specimen $[17,18]$ but such an investigation was beyond the scope of the current study.

\subsection{Push-through testing}

Initially, the response of the specimen in push-through was determined. Three specimen were driven past the second load drop peak, for confirming the general curve character, the initial and second load peak/load drop levels. A representation of the recorded response is shown in figure 3. Out of the drafted response in push-through, the displacement levels beyond the first load drop, based on the number of available test specimens, where chosen at about $+0.3 \mathrm{~mm}$ and $+0.6 \mathrm{~mm}$ after the first load drop.

Overall, 13 specimen were damaged in push-through, four just past the first load drop, three at $+0.3 \mathrm{~mm}$ and three more at $+0.6 \mathrm{~mm}$ bolt head travel distance past the first load 
drop and three past the second load drop. In figure 6, representative push-through load displacement curves from each specimen category is shown. Out of the 16 specimen in total, nine were subsequently tested in bearing. The testing and inspection program is depicted in table 1.

Specimens from each category were sectioned for optical microscopy observation. For the optical microscopy, two reference planes where used for imaging, planes A and B as shown in figure 7.

As being reported in the literature $[10,11]$, the specimen being pushed-through right past the first load drop, exhibited a single profound inter-laminar delamination crack at about the middle thickness of the plate, similar to the one shown in figure 8a. For the current study and for the specimen sections according to figure 7 , the cracks on these cross sectional planes were not exactly at the middle of the laminate thickness, since delamination fracture favors inter-laminar planes of different fiber direction whilst in these specimen, layers of the same fiber direction were at the symmetry plane. Around the periphery of the bolt and about mid-plane location, shear cracks were generated tangent to the bolt head and parallel to the fibers of the lamina in that ply, as shown in figure $8 \mathrm{~b}$. For larger push-through displacements, the shear cracks were expanding along the fiber direction whilst more inter-laminar cracks, typically three to four were nucleated, shown in figure 8c. The intra-laminar shear cracks which initiated mainly underneath the bolt head and expanding along the fiber direction of that ply where bridged with inter-laminar delaminations.

\subsection{Bolt bearing load testing after push-through}

The bearing test results from the specimens that were damaged just past the first load drop in push-through (specimens 8,9 and 10) did not exhibit any significant drop in the bearing strength from the pristine ones (specimens 1,2 and 3) while the test result in terms of bearing strength deviated within the expected limits due to statistical scatter. In figure 9, a representative bearing curve for the pristine specimen is depicted which was representative as well to the response of the set of lightly damaged specimen in pushthrough. Past the first load drop in push-through, the bearing curves exhibited a distinctive drop in the bearing strength and that seemed to depend on the damage levels inflicted by the push-through loading phase. The bigger the transverse displacement 
from push-through, the more the damage and the greater the reduction in the bearing strength. In figure 10, representative sections dictated that the more the inter-laminar splits and the shear cracks caused at a higher push-through translation, the easier the creation of the shear cracks on that intersection plane from the bearing load. This fracture pattern indicated that a single thick laminate, is more resistant in bearing than being subdivided in more separated sub-laminates, for carrying an equal amount of load. The bearing test results are shown in figure 9. In essence, for the CFRP material employed in this study and for the specific specimen design:

- No bearing strength reduction was evidenced for the specimens that had prior been damaged under push-through loading, where the push-through displacement stopped just past the first load drop of the push-through load curve $\left(\sigma_{b, \text { load drop }}=\right.$ $\left.\sigma_{b, \text { prisitne }}\right)$

- There was a reduction in the bearing strength for the specimens damaged under the arbitrarily selected push-through distance travel of $+0.3 \mathrm{~mm}$ past the first load drop $\left(\sigma_{b, 0.3}<\sigma_{b, p r i s i t n e}\right)$. On the subsequent bearing tests, the bearing strength load curve recovered past the $\sigma_{b, 0.3}$ bearing failure level

- There was a further reduction in the bearing strength for the specimens damaged under the arbitrarily selected push-through distance travel of $+0.6 \mathrm{~mm}$ past the first load drop $\left(\sigma_{b, 0.6}<\sigma_{b, 0.3}<\sigma_{b, p r i s i t n e}\right)$. On the subsequent bearing tests, the bearing strength load curve did not recover past the $\sigma_{b, 0.6}$ bearing failure level

The above mentioned study findings are herein discussed when placed within the context of aircraft airworthiness regulations and certification.

\section{Results discussion within the context of airworthiness and safety}

Civil and military aircraft airworthiness certification specifications form a part in the means of controlling and ensuring the safety of flight. Within such specifications, as for large civil aircraft for example [5, 6], the expected performance criteria for airframe structures are captured. According to the specifications clauses relevant to the investigation, airframe structures must $(*)$ :

- Function properly under the application of the maximum service loading applied quasi-statically without exhibiting signs of detrimental permanent deformation or 
deformation levels that interfere with the proper operation of the aircraft. The maximum service loading level, which is to be met once in a structural life time, is defined as Limit Loading (LL)

- Not fail under the application of the maximum service loading applied quasistatically, multiplied by a safety factor which in the majority of the cases equals to 1.5. This loading level is defined as Ultimate Loading (UL) and UL= LL x 1.5

- The structure has to be able to withstand static Ultimate Loading conditions whilst containing certain levels of damage that are reasonably expected to occur during service. In this study and for the scenario under investigation, different levels of pull-through damage are regarded as reasonably occurring events that the structure has to show its sustained resilience to.

(*) The above statements are simplified expressions employed for providing with a simplistic translation to the actual certification specifications and should not be regarded as substitutes to the actual airworthiness certification specification clauses. Joint fitting factors or other material/design factors that are also employed for joint sizing are not discussed herein to avoid masking the essence of the study with additional complications

Airworthiness certification specifications require proof of structural performance for the different loading types and loading levels as described above. The maximum loading to be met in service, which is the Limit Loading (LL), when multiplied by the safety factor of 1.5 , has to be less or equal to the specimen's bearing strength. The majority of the aircraft component loading to be encountered in service is expected to be smaller than LL. In service loading, in most of the cases, is variable in magnitude; statistical distributions of the probability of the loading level occurrence in terms of number of cycles are generated based on experience and in-service flight test measurements. Although in service expected loading is variable in nature, it is a certification requirement to provide proof that the structure is able to endure loading applied in a quasi-static format, according to the first and second bullet points mentioned above and even at the reasonably expected damaged state as per the third bullet point. The concept of structural damage tolerance which is incorporated within the airworthiness specifications, could be applied by incorporating the idea of a fail-safe design, meaning that in the case of a structural component failing hence being incapable 
of resisting imposed loading as effectively, the applied load will be re-directed to alternate structural components. It is very rare for a single bolt on a joint to account for the load transfer between structural parts mated together. Most of the times, assemblies of many bolts arranged in a pattern are used which embed this fail safety character, as long as the remaining of the bolts if some of them fail, are capable of providing with the required structural performance.

In structural designs comprised of metallic material components, the inherent material plasticity of the assembled parts, aids with distributing the load within the bolt pattern from stiffer locations to less stiff ones and this is a design practice which is allowed to take place even below LL conditions on occasions. A lighter structural design can be the result of carefully designing the structure to undergo local plasticity at extreme loading, making sure that the structural performance dictated by the regulations is maintained. Generally speaking, fatigue failure will be the main driver for bolted joint sizing on aluminum airframe structures. Current practice for bolted joint sizing on CFRP laminates, follows the idea of retaining the stress levels around the bolt-holes of a bolt pattern below certain levels according to a prescribed failure theory for laminated composites. The loading on bolt-holes is conceived in terms of bypass, meaning the loading flowing around the laminate not generated by the current fastener in question and in terms of bearing load from the fastener. Interaction charts relate the bi-directional nature on the bypass loading on the laminate with the bearing load and the overall expected performance. Interaction with pull-through loading is generally disregarded since joints are designed in a way to avoid the loading in that direction. Nevertheless, as explained during the introduction, transverse loading which may cause pull-through failure will be a component of the loading eccentricity generated in single lap joints, be the result of manufacturing and assembly tolerances mismatches or defects, can result from thermal expansion and mismatch, from non-anticipated structural overloading or damage from foreign object impact. According to the third bullet point in this section and especially for CFRP structures, wherever a structural joint may be prone to pull-through damage, certification regulations dictate that compliance with the structural performance requirements need to be proven for the structure in its damaged state.

The push-through load displacement curve for the current material and specimen design and geometry tested shown in figure 3, matched the expected output described by 
the ASTM D7332 procedure, exhibiting a distinct first load peak followed by a second one further on. Current design practice will assume that the joint UL case would not drive the structure past the first load peak on that chart. The fail-safe characteristics embedded in that response are that even in the adverse situation of a structure overcoming the first load peak, the stiffness of the joint in the transverse direction is almost halved on the specimen tested, as shown by lines (a) and (b) on figure 11, hence the increased local compliance will aid the load shedding to other locations on the structure. Also, the second peak is at a higher level than the first one which means that an even higher load needs to be present in order to catastrophically fail the part of the joint. In that state, it is highly unlikely for the structure to fail if assumed that the maximum load to be met in service (LL) in this case should be about $7 \mathrm{kN}(=10.5 \mathrm{kN} /$ 1.5). In view of augmenting the loading utilization of the joint regarding pull-through failure as an isolated event, the structure could potentially be allowed temporarily to venture past the first peak on certain scenarios, provided there could be some repeatability in the response past the initial damage state, the LL level would be below the first load peak and that the load shedding to other structural members after passing the first load peak, would be effectively carried by safely.

In the current analysis though, the aim was to explore the safe utilization of the joint in bearing following the pull-through event. The bearing test load displacement curve for the undamaged specimen and the damaged ones in push-through just past the first load drop in push-through testing, exhibited similar response. It was shown in [19] that pre-tightening of the fastened joined helped with an apparent increase in the bearing strength. It is expected, although not tested, for pre-tightening to have a similar effect up to a certain extend in the case of damaged joints by pull-through, by clutching the split sub-laminates together. The specimen in the current study were tested free of pretightening.

In the case of bolted joints on FRP laminates, the airworthiness specifications interpretation are demonstrated in figure 12. In figure 12, the bearing load-displacement curves are displayed, subjected to quasi-static tensile loading. On the loading axis, ultimate loading (UL) is marked as the region of the specimen's bearing strength. For all the damaged in push-through specimen in the current study, the drop in the bearing strength was not below the LL level, specimen of different material and /or design may 
suggest otherwise. For the specimen with $+0.3 \mathrm{~mm}$ travelled distance past the drop in push-through, the bearing curve past the failure strength $\sigma_{b, 0.3}$ recovered and showed signs of load carrying capability equal more or less with the reduced bearing strength $\sigma_{b, 0.3}$, while this is not the case for the specimens pushed-through at $+0.6 \mathrm{~mm}$.

For the bearing case, if damage caused by push-through failure or similar could be assumed just past the first load drop, then this is damage that could be sustained and the airworthiness requirements are not breached in terms of strength since UL could still be safely carried by the structure. For the other two cases, the UL condition is not fulfilled hence the airworthiness requirements are breached, but the aircraft is safe to operate until servicing, since the structure could still carry LL conditions. In the first case of $+0.3 \mathrm{~mm}$ push-through travel, the failsafe characteristic were still present by the means of the structure being more compliant and still be able to sustain certain load above LL. For the second case, the fail safety character was not present any longer and the bearing strength dropped below LL.

Concluding to the discussion, regarding the current study material and specimen, maximum load in pull-through should be assumed the first load drop in the pushthrough curve, since past that loading the bearing behavior under UL conditions was affected. Under adverse joint loading conditions, where pull-through damage has been generated, the structure can safely carry Limit Loading and depending on the severity of the damage, even retain its fail safety character when embedded in a structure with alternative loading paths. Obviously, the discussion above was based on the specific CFRP material and specimen design used. It is expected that specimen of different material and layup configuration will deviate from the exhibited behavior. The discussion presented the key elements and the thought process for finding whether a damaged bolted joint from pull-through could continue to function safely within the bounds of airworthiness requirements. The analysis presented, bears some of the features of metallic joints sizing under plasticity and as long as the structural performance could be guaranteed, the process may eventually help with designing lighter structures. 


\section{Conclusions}

A modified testing procedure was proposed for investigating the static bearing strength reduction of FRP laminate bolted joints that have prior been damaged by a pull through event or by events generating similar types of damage caused by transverse to the laminate thickness loading. It was found that for the material and the specimen design used and for the level of damage inflicted on the specimens, the reduction in the joint bearing strength was up to $13 \%$ from its original undamaged state. The modified testing procedure could be utilized for bolted joints loaded in bearing but expected to suffer from transverse loading damage during service.

Structural strength is defined by proper interpretation of the industry regulations in question, which where the airworthiness certification specifications in the current study. The experimental survey showcased the application of these regulation to the pull-though failure of bolted joints followed by bearing load damage tolerance scenario and sketched the bounds within which the joint could be assumed to retain its required structural performance. 
Table 1: Testing and inspection program

\begin{tabular}{|c|c|c|c|c|}
\hline Specimen No & $\begin{array}{l}\text { Push- through } \\
\text { loading level }\end{array}$ & Inspection & Bearing loading & Inspection \\
\hline $1,2,3$ & $\mathrm{x}$ & $\mathrm{x}$ & $\begin{array}{l}\text { Bearing loading } \\
\text { to failure }\end{array}$ & $\begin{array}{c}\text { Sectioned / opt } \\
\text { microscopy }\end{array}$ \\
\hline $4,5,6$ & Until final failure & $\begin{array}{l}\text { Sectioned / opt } \\
\text { microscopy }\end{array}$ & $\mathrm{x}$ & $\mathrm{x}$ \\
\hline 7 & At first load drop & $\begin{array}{l}\text { Sectioned / opt } \\
\text { microscopy }\end{array}$ & $\mathrm{x}$ & $\mathrm{x}$ \\
\hline 8,9 & At first load drop & $\mathrm{x}$ & $\begin{array}{l}\text { Bearing loading } \\
\text { to failure }\end{array}$ & $\mathrm{x}$ \\
\hline 10 & At first load drop & $\mathrm{x}$ & $\begin{array}{l}\text { Bearing loading } \\
\text { to failure }\end{array}$ & $\begin{array}{l}\text { Sectioned / opt } \\
\text { microscopy }\end{array}$ \\
\hline 11 & $\begin{array}{l}\text { at } 1.1 \mathrm{~mm} \text { of total } \\
\text { transverse displ }\end{array}$ & $\begin{array}{l}\text { Sectioned / opt } \\
\text { microscopy }\end{array}$ & $\mathrm{x}$ & $\mathrm{x}$ \\
\hline 12,13 & $\begin{array}{l}\text { at } 1.1 \mathrm{~mm} \text { of total } \\
\text { transverse displ }\end{array}$ & $\mathrm{x}$ & $\begin{array}{l}\text { Bearing loading } \\
\text { to failure }\end{array}$ & $\begin{array}{l}\text { Sectioned / opt } \\
\text { microscopy }\end{array}$ \\
\hline 14 & $\begin{array}{l}\text { at } 1.4 \mathrm{~mm} \text { of total } \\
\text { transverse displ }\end{array}$ & $\begin{array}{l}\text { Sectioned / opt } \\
\text { microscopy }\end{array}$ & $\mathrm{x}$ & $\mathrm{x}$ \\
\hline 15,16 & $\begin{array}{l}\text { at } 1.4 \mathrm{~mm} \text { of total } \\
\text { transverse displ }\end{array}$ & $\mathrm{x}$ & $\begin{array}{l}\text { Bearing loading } \\
\text { to failure }\end{array}$ & $\begin{array}{l}\text { Sectioned / opt } \\
\text { microscopy }\end{array}$ \\
\hline
\end{tabular}




\section{Figure Captions}

Figure 1: The two-step quasi-static loading experimental approach: a) pull-through loading and initial damage, followed by b) bearing tensile loading and superimposed bearing damage

Figure 2: The push-through testing phase, a) bolt push-through fixture, b) cutaway section of the specimen in position and c) specimen under bolt push through loading

Figure 3: Representative push-through load/displacement curve

Figure 4: Image for depicting the location and extents of cracks with respect to the outer fixture rim

Figure 5: Bearing loading testing procedure, a) double lap configuration without bolt pre-tightening load and $\mathrm{b}$ ) bearing test

Figure 6: Push-through testing, stopped at various transverse displacement levels

Figure 7: Plane definition and location for the optical microscopy imaging

Figure 8: Sectioned specimens with push-though damage, a) profound central delamination, b) shear crack underneath bolt head, c) increasing number of delaminations past the first load drop

Figure 9: Bearing stress vs strain curves for the pristine and damaged specimen

Figure 10: Damaged specimens in bearing a) $+0.3 \mathrm{~mm}$ in push through/fewer interlaminar delaminations b) $+0.6 \mathrm{~mm}$ in push through/more delaminations

Figure 11: Reduction in the transverse stiffness of a damaged bolted joint

Figure 12: Bearing test results and airworthiness considerations 


\section{References}

[1] Niu MCY. Composite Airframe Structures. Hong Kong Conmilit Press Ltd; 1995

[2] Niu MCY. Airframe Stress Analysis and Sizing. Hong Kong Conmilit Press Ltd; 1997

[3] Camanho PP, Tong L. Composite Joints and Connections. Woodhead Publishing Limited; 2011

[4] A.A. Baker \& M.L. Scott. Composite Materials for Aircraft Structures. AIAA educational series; 2016

[5]EASA. Certification specifications and acceptable means of compliance for large aeroplanes CS-25. Amend 17; 2017.

[6]EASA. Acceptable Means of Compliance - Composite Aircraft Structure AMC 20$29 ; 2010$.

[7] Davies G, Irving P. Impact, Post-Impact Strength and Post-Impact Fatigue Behaviour of Polymer Composites. Irving P, Soutis C editors. Polymer Composites in the Aerospace Industry, Cambridge: Woodhead Publishing, 2015; pp. 216-109 [8] ASTM D7332. Standard test method for measuring the fastener pull-through resistance of a fiber-reinforced polymer matrix composite. American Society for Testing and Materials; 2013.

[9] CMH-17, Composites Material Handbook. SAE International; 2012

[10] Banbury A, Kelly DW. A study of fastener pull-through failure of composite laminates. Part 1: Experimental. Compos Struct 1999; 45:241-54.

[11] Banbury A, Kelly DW, Jain LK. A study of fastener pull-through failure of composite laminates. Part 2: Failure prediction. Compos Struct 1999; 45:255-70.

[12] Elder DJ, Verdaasdonk AH, Thomson RS. Fastener pull-through in a carbon fibre epoxy composite joint. Compos Struct 2008; 86:291-298.

[13] Adam L et all. Discrete ply model of circular pull-through test of fasteners in laminates. Compos Struct 2012; 94:3082-3091.

[14] ASTM D5961. Standard Test Method for Bearing Response of Polymer Matrix Composite Laminates. American Society for Testing and Materials; 2013.

[15] Roark RJ, Young WC. Formulas for Stress and Strain, 5e. McGraw Hill; 1984

[16] Camanho PP, Lambert M. A design methodology for mechanically fastened joints in laminated composite materials. Compos SciTechnol 2006; 66(15):3004-3020. 
[17] Ascione F, Feo L, Maceri F. An experimental investigation on the bearing failure load of glass fibre/epoxy laminates. Composites Part B: Engineering, 2009; 40:197-205. [18] Ascione F, Feo L, Maceri F. On the pin-bearing failure load of GFRP bolted laminates: An experimental analysis on the influence of bolt diameter. Composites Part B: Engineering, 2010; 41:482-490.

[19] Giannopoulos KI et all. Effects of bolt torque tightening on the strength and fatigue life of airframe FRP laminate bolted joints. Composites Part B: Engineering, $2017 ; 125: 19-26$. 


\section{Damage tolerance of CFRP airframe bolted joints in bearing, following bolt pull-through failure}

Giannopoulos, loannis K.

Elsevier

Giannopoulos IK, Grafton K, Guo S, Smith H. (2020) Damage tolerance of CFRP airframe bolted joints in bearing, following bolt pull-through failure. Composites Part B: Engineering, Volume 185, March 2020, Article number 107766 https://doi.org/10.1016/j.compositesb.2020.107766

Downloaded from Cranfield Library Services E-Repository 